\title{
KEMAMPUAN TIK GURU DAN TENAGA KEPENDIDIKAN (SDM) BERPERAN DALAM PENINGKATAKAN E-LEARNING DAN E-GOVERNANCE
}

\author{
Oleh
}

\section{Masluyah Suib ${ }^{1}$}

\begin{abstract}
Abstrak :Ketersediaan SDM TIK yang berkualitas serta memenuhi standard kompetensi TIK merupakan tantangan dan permasalahan. Unsur SDM guru/tenaga kependidikan merupakan pihak yang dipandang paling bertanggungjawab terhadap keberhasilan implementsi TIK. Sumber daya manusia dan modal intelektual (intellectual capital) merupakan aset yang sangat penting dalam menciptakan keunggulan bersaing yang langgeng. Sistem kebijakan publik adalah tatanan kelembagaan yang berperan atau merupakan "wahana" dalam penyelenggaraan sebagian atau keseluruhan "proses kebijakan" (formulasi, inplementasi dan evaluasi kinerja kebijakan) yang mengakomodasikan kegiatan teknis (Technical Process) maupun sosiopolitis (Sociopolitical Process) Keberhasilan kebijakan dalam implementasi, tentunya tergantung pada komitmen, kesungguhan, ketekunan, teraktualisasi dalam mutu kinerja para pelaksana (SDM) nya.
\end{abstract}

Kata Kunci: Sistem kebijakan public, Unsur SDM, dan keberhasilan implementasi TIK

\section{Pendahuluan}

Untuk mengoptimalkan keber-hasilan pendidikan diperlukan kebijakan pembangunan nasional yang tepat. Kebijakan yang dikeluarkan oleh pemerintah sudah begitu banyak, namun dalam implementasinya membuahkan kesenjangan dan keresahan, yang menimbulkan masalah baru.

Renstra Departemen Pendi-dikan Nasional Tahun 2010-2014 memuat enam strategi yaitu (1) Perluasan dan Pemerataan Akses Pendidikan Usia Dini (PAUD) Bermutu dan Berkesetaraan Gender; (2) Perluasan dan Pemerataan Akses Pendidikan Dasar Universal Bermutu dan Berkesetaraan

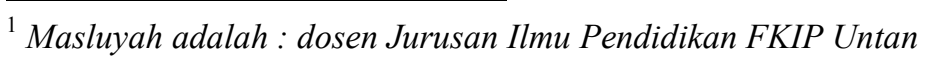


Gender; (3) Perluasan dan Pemerataan Akses Pendidikan Menengah Bermutu, Berkesetaraan Gender, dan Relevan dengan Kebutuhan Masyarakat; (4) Perluasan dan Pemerataan Akses Pendidikan Tinggi Bermutu, Berdaya Saing Internasional, Berkesetaraan Gender dan Relevan dengan Kebutuhan Bangsa dan Negara; (5) Perluasan dan Pemerataan Akses Pendidikan Orang Dewasa Berkelanjutan yang Berkesetaraan Gender dan Relevan dengan Kebutuhan Masyarakat; dan (6) Penguatan Tata Kelola, Sistem Pengendalian

Peningkatan mutu guru melalui perangkat komputerisasi dengan program Information and Communications Technology (ICT) merupakan kebijakan yang baru dilaksanakan oleh Pemerintah Indonesia, sebagaimana dikemukakan berikut ini:

Tepat tanggal 7 Juli 2007 (07-07-07), Biro PKLN merilis Media Jardiknas yang didesain sebagai Pusat Sumber Belajar (PSB) berbasis multimedia bagi semua jenjang pendidikan, dari Pra-Sekolah sampai Perguruan Tinggi serta Pendidikan Luar Sekolah. Selain sebagai PSB, Media Jardiknas juga berfungsi sebagai bank bahan ajar yang dikembangkan bersama dari, oleh dan untuk Guru/Dosen/Widyaiswara. Dengan demikian diharapkan kontennya selalu aktual terhadap kurikulum yang berlaku saat ini (KTSP) dan yang akan datang.

Dalam rangka pengembangan TIK di bidang pendidikan, ketersediaan SDM TIK yang berkualitas serta memenuhi standard kompetensi TIK merupakan tantangan dan permasalahan. Unsur SDM guru/tenaga kependidikan merupakan pihak yang dipandang paling bertanggungjawab terhadap keberha-silan implementsi TIK. Aspek sumber daya manusia (SDM), tata kelola, kelembagaan, dan penganggaran menjadi topik-topik inti sebagai suatu cerminan sejauh mana dan bagaimana TIK telah diimplementasikan oleh guru dalam meningkatkan pembelajarannya dan peningkatan e-governance bagi tenaga kependidikannya. Sebagaimana dika-takan berikut ini; Keterbatasan Sumberdaya manusia/pegawai (dalam hal ini, Guru/tenaga kependidikan) yang menjalankan implementasi teknologi informasi pada e-learning dan e-governance merupakan hambatan utama, selain penyediaan sarana dan prasarana teknologi informasi, dan lembaga yang menangani implementasi e-government. (Hadwi Soendjoyo, 2005).

Dalam proses implementasi e-learning dan e-governance, masalah ketersedia-an sumberdaya manusia yang mempunyai standar kompetensi dibidang teknologi informasi dan komunikasi masih sulit ditemukan. Dari peryataan di atas jelas menunjukkan bahwa Keberhasilan implementasi suatu kebijakan pendidikan terletak pada kemampuan para pelaksananya. Terkait 
dengan upaya pemenuhan kebutuhan penyediaan sistem informai tenaga kependidikan, berhubungan dengan tingkat pendidikan, keahlian, pengetahuan, dan pengalaman guru dan tenaga kependidikan dalam memahami masalah operasional pemanfaatan TIK. John A. Quelch \& Helen Bloom dalam artikelnya "Ten Steps to a global Human Resource Strategy", menyebutkan bahwa tantangan SDM global ditandai dengan pesatnya pertumbuhan masyarakat yang berpendidikan, semakin banyak negara-negara yang menyadari bahwa sumber daya manusia dan modal intelektual (intellectual capital) merupakan aset yang sangat penting dalam menciptakan keunggulan bersaing yang langgeng. Pesatnya perkem-bangan TIK dan tantangan TIK yang dihadapi Pemerintah khususnya bidang pendidikan saat ini menghasilkan pemikiran dan perencanaan / kebijakan strategis bahwa sudah selayaknya kualitas pengetahuan, keterampilan dan profesionalisme guru/tenaga kependidikan dibidang TIK diting-katkan agar mampu mengoperasikan dan memanfaatkan sarana prasarana TIK secara benar, prosedural dan optimal. Kemampuan mengelola TIK bagi lembaga menjadi kebutuhan dan prioritas strategis

\section{Konsepsi Kebijakan Pendidikan}

Menurut Patton dan Sawicki, (1986:p:38) Kebijakan adalah Suatu Tindakan yang dimantapkan untuk diikuti oleh Suatu Badan Pemerintah atau lembaga/institusi, yang seringkali menggunakan sinonim untuk Perencanaan dan Program. Selan-jutnya dikatakan Patton dan Sawick, (1986;p:15) Analisis kebijakan adalah sebuah proses yang biasanya diawali dengan definisi masalah dan pada fase pencarian proses perencanaan yang lebih luas, memberi alternatif pilihan, namun dokumen akhirnya dapat berupa memo/catatan kecil, makalah, atau draf perundang-undangan

Analisis kebijakan dapat dipandang sebagai proses berar-gumentasi dan berdebat untuk menciptakan, mengkaji secara kritis, dan mengkomunikasikan keyakinan yang plausible benar tentang kinerja dari proses pembuatan kebijakan (William N. Dunn, 2000: 143). Kebijakan Pendidikan adalah keputusan-keputusan yang berkaitan dengan perbaikan dan penyempurnaan penyelenggaraan pendidikan (Fakry Gaffar, 2008). Selanjutnya Jones (1977:14) menganalisis komponen-komponen pengertian kebijakan pendidikan yang meliputi : (1) Goal atau tujuan yang diinginkan, (2) Plan atau proposal, yaitu pengertian yang spesifik untuk mencapai tujuan, (3) Program, yaitu upaya yang berwenang untuk mencapai tujuan, (4) Decision (keputusan), ialah tindakan-tindakan untuk menentukan tujuan, membuat rencana, melaksanakan, menilai rencana, (5) Effect, yaitu akibatakibat dari rencana (disengaja atau tidak, primer atau sekunder, diperhitungkan sebelumnya atau tidak, diestimasi sebelumnya atau tidak). 


\section{Sistem Kebijakan Pendidikan}

Menurut Professor Dunn, sistem kebijakan yaitu bidang ilmu pengetahuan dan profesi yang mempelajari dan menangani masalah manajemen (pengelolaan) proses kebijakan publik dalam keseluruhan tahapan kebijakan (policy cycle) dalam interdependensinya dengan kompleksitas dan dinamika sistem kebijakan (policy system). Selanjutnya dikatakan bahwa, unsur dalam sistem kebijakan adalah (1). Stakeholders kebijakan, (2). Kebijakan public (Policy content) dan (3). Lingkungan Kebijakan (Policy Environment)

Secara konseptual terdapat dua unsur penting dalam setiap substansi kebijakan yaitu (a) sejumlah tujuan kebijakan = meningkatkan mutu pendidikan (ends, atau policy objectives $=Y i$ ) dan (b) sejumlah alat untuk mencapai tujuan= memberikan pembelajaran/pelatikan TIK kepada guru -guru/tenaga kependidikan (means, atau policy instrumens $=X n$. Saling hubungan antar (a) dan (b) dapat diekspresikan secara matematis sebagai $\mathrm{Yi}=\mathrm{f}(\mathrm{Xi})$, dimana $\mathrm{Yi}$ merupakan variable dependen yaitu sejumlah tujuan= meningkatkan mutu pendidikan dengan mengembangkan kemampuan TIK guru/tenaga kependidikan, sedang Xi merupakan variable independent yaitu sejumlah alat atau sebab-sebab = pembelajaran dan pelatihan TIK guru/tenaga kependidikan yang dapat menimbulkan akibat yang diinginkan $=$ mutu pembelajaran pelayanan akademik meningkat yang berujung pada peningkatan mutu pendidikan, terdapat kemungkinan bahwa factor $\mathrm{Xi}$ dipengaruhi pula oleh berbagai factor lainnya (Zi).

Sistem kebijakan publik adalah tatanan kelembagaan yang berperan atau merupakan "wahana" dalam penyelenggaraan sebagian atau keseluruhan "proses kebijakan" (formulasi, inplementasi dan evaluasi kinerja kebijakan) yang mengako-modasikan kegiatan teknis (Technical Process) maupun sosiopolitis (Sociopolitical Process) serta saling hubungan atau interaksi antar empat faktor dinamik, yaitu : (1). Lingkungan kebijakan (LK) = lingkungan pendidikan dengan isu,dari guru dan tenaga kependidikan. Rendahnya mutu pendidikan dikarenakan rendahnya mutu pembelajaran dan layanan akademik, isu tersebut diatasi dengan kebijakan pemberian pembelajaran dan pelatihan TIK kepada guru dan tenaga kependidikan; (2). Pengelolaan kebijakan (PK) adalah Depdiknas Pusat/daerah dan perangkatnya yang berperan dalam proses kebijakan, yang menentukan kebijakan atau tahap lainnya seperti pelaksanaan, pengawasan dan penilaian atas hasil atau kinerja yang dicapai.; (3). Kebijakan itu sendiri (KP) adalah keputusan diadakannya pembelajaran dan pelatihan bagi guru dan tenaga kependidikan seluruh Indonesia secara bertahap untuk meningkatkan 
kinerja/profesionalitas mereka; (4). Kelompok sasaran kebijakan (KS) adalah Guru dan Tenaga Kependidikan (Mustopadidjaja AR, 1988). LK menghadapi berbagai substansi kebijakan yang diusung berbagai stakeholder. Demikian pula PK yang harus merespon berbagai masalah kebijakan terdiri dari sejumlah stakeholder. Dalam hubungan tersebut para pejabat public harus memperhatikan posisi dan kondisi KS. Struktur dan dinamika "policy system tersebut menandai/berlangsung pada keseluruhan tahap "policy cycle" (formulasi, implementasi dan evaluasi kinerja). Disamping dimensi teknis mengandung dimensi Sosiopolitis. Evaluasi kinerja dilakukan dalam rangka pemantauan, pengawasan, pemeriksaan dan pertanggung jawaban, yang hasilnya memberikan masukan (feed back) dalam proses formulasi dan implementasi selanjutnya.

\section{Konsep dan Prinsip Implementasi dan Pengendalian Kebijakan}

\section{Konsep}

Unsur SDM organisasi merupakan pihak yang dipandang paling bertanggung-jawab terhadap keberhasilan implementai kebijakan. Pengembangan kompetensi SDM (guru/tenaga kependidikan) merupakan pilihan yang tepat untuk mengawal/-mendukung keberhasilan implementasi kebijakan, di samping ketersediaan anggaran menjadi faktor penting dalam penentuan kebijakan perencanaan, kelembagaan, dan pengganggaran operasionalisasi implementasi kebijakan.

Selanjutnya Chaeles O. Jones (1984) mengatakan bahwa Implementasi proses adalah suatu proses mendapatkan sumber tambahan sehingga dapat memperhi-tungkan apa yang harus dikerjakan. Berikut Jeffrey L dan Aaron B. Vildavsky, mendefinisikan dengan jelas tentang Pelaksanaan Imple-mentasi tersebut yaitu: Implementasi bisa digambarkan sebagai proses dari interaksi antara suatu keberhasilan dan upaya pelak-sanaan untuk dapat mewujudkannya. Program Implementasi hingga kini menjadi jaringan yang tidak berurutan.

\section{Herarki}

Pelaksanaan dan pengendalian kebijakan merupakan mata rantai perlengkapan dalam proses kebijakan Publik. Kebijakan publik yang telah disahkan dan telah dicantumkan dalam lembaga Negara/ lembaran daerah siap untuk dilaksanakan. Kebijakan publik ada yang self-executing (yaitu dengan sendirinya telah terimplika-sikan begitu suatu kebijakan public ditetapkan) seperti pengaturan kedaulatan suatu negara. Jumlah kebijakan 
publik yang "self-executing” ini relatif sangat sedikit. Umumnya kebijakan publik adalah "non self-executing" dan harus dilaksanakan dan dikendalikan oleh yang berwenang yang terdiri dari berbagai pihak, terutama Lembaga Eksekutif, birokrat dan badan-badan Pemerintah serta Badan Legislatif (DPR, DPRD) yudikatif dan kelompok-kelompok kepentingan masyarakat. Sejalan dengan itu dikatakan oleh Fakry (2008), Daya dukung SDM : (1) SDM memiliki fungsi strategik untuk keberhasilan dalam implementasi kebijakan ; (2) SDM terdiri dari Policy Exexutioner dan policy supporters ; (3) Policy executioner memiliki ciri-ciri: Profesional, Team Leadership, Transparancy, Emowering dan Accuntability; (4) Supporters: Profesional.

Implementasi dan pengendalian kebijakan publik ditujukan agar tujuan dikeluarkannya kebijakan publik dapat segera tercapai dengan dampak negarif yang sekecil mungkin.

\section{Prinsip}

a. Sifat kebijakan publik, self-executing atau non self-executing.

b. Siapa yang paling bertang-gung jawab, ekskutif, legislative, yudikatif, Badan badan Pemerintah/ Lembaga Negara lainnya, asosiasi perusahaan swasta dan pemerintah, LSM dan masyarakat.

c. Pelaksanaan dan pengendalian kebijakan publik dilakukan secara simultan.

d. Orientasi pada sasaran dan tujuan serta target group dari kebijkan publik.

e. Efektif, efisien dalam penggunaan sumberdaya.

f. Berdasakan prosedur dan tata laksana pelaksanaan yang ditetapkan.

g. Tertib hukum, tertib administrasi.

h. Akuntabilitas pelaksanaan.

\section{Teknik Implementasi Ke-bijakan dan Pengendalian}

a. Kebijakan Publik ditentukan Oleh Hirarki dan Kategori Kebijakan lazimnya

dirumuskan dalam bentuk perundang-undangan yang hirarkinya sebagai berikut : UUD 1945; UU/ Perpu; Peraturan Pemerintah; Peraturan Presiden; Peraturan Daerah

b. Tahapan Implementasi dan Pengendalian Kebijakan Pub-lik : Menurut Fakry (2008);

Tahapan Implementasi: (1) Tahapan Implementasi terdiri dari: Adopsi, sosialisasi, persiapan, dan action; (2) Adopsi adalah proses menjadikan kebijakan sebagai keputusan formal yang mengikat semua orang; (3) Bentuk adopsi Surat Keputusan Formal dari Institusi berwenang; (4) 
Adopsi keputusan legal dengan kekuatan legal; (5) Sosialisasi penyebarluasan keputusan hasil adopsi dalam berbagai bentuk; (6) Sosialisasi mengundang reaksi publik untuk mendukung, menolak atau bersikap netral; (7) Masukan untuk mengembangkan strategi implementasi: (8) Persiapan adalah tahapan pemeriksaan dan pengecekan akhir seluruh unsur untuk action; (9) Persiapan adalah langkah pertama action; (10) Action adalah tindakan nyata implementasi kebijakan dengan mengerahkan seluruh fors untuk menggerakkan Organisasi Marchinary $(\mathrm{OM})$ dalam membawa keseluruhan unsur kebijakan dalam perbuatan nyata; (11) Action dalam kebijakan keseluruhan proses gerakan dari kondisi pertama menuju kondisi baru yang dicita-citakan; (12) Action digerakan oleh policy executioner dengan bantuan seluruh staff pendukung yang profesional.

\section{Urutan Langkah Pelaksanaan dan Pengendalian kebijakan}

1. Sosialisai dan deseminasi kebijakan, agar seluruh masyarakat mengetahui tentang adanya kebijakan tersebut.

2. Pembentukan organisasi pelaksa-naan pembelajaran dan pelatihan TIK e-learning dan e-governance, mencakup: pemba-gian tugas dan fungsi; Penyusunan lembaga/ unit kerja.; Tata kerja dan juklak.; Koordinasi.

3. Penyusunan Program Kerja pelaksanaan pembelajaran dan pelatihan TIK e- learning dan e-governance dengan memper-hatikan : Hirarki; Kategori; Sistem dan Proses Pengelolaan kebijakan; Faktor-faktor yang mempengaruhi dinamika dan Proses Pembuatan kebijakan dan Pelaksanaannya.; Pemahaman terhadap masalah yang perlu dipecahkan melalui kebijakan ini.

4. Perincian Program Kerja :meliputi: Volume target; Sumber daya dan besarnya;

Sumber daya alam; Sumber daya manusia; Sumber dana; Waktu dan networking pelaksanaan (Bar-chart, NMP, dll); Sarana dan prasarana.

5. Pelaporan secara berkala hasil pelaksanaan untuk : Pengen-dalian; Bahan evaluasi; Bahan pertanggungjawaban.

\section{Esensi Implementasi Kebijakan Peningkatan Mutu Pendidikan (melalui TIK e-Learning dan e- Governance)}

1. Implementasi kebijakan TIK e-learning dan e-governance merupakan mata rantai penting dalam proses kebijakan pendidikan. 
2. Implementasi kebijakan TIK e-learning dan e-governance merupakan sarana terpenting dalam mewujudkan pening-katan mutu pendidikan.

3. Implementasi kebijakan TIK e-learnig dan governance dapat dilakukan oleh : Instansi pemerintah (Dep-diknas dan perangkatnya); guru-guru dan tenaga kepen-didikan.

4. Implementasi kebijakan TIK e-learnig dan governance adalah kebijakan Opera-sional.

5. Dampak implementasi kebi-jakan TIK e-learnig dan governance dirasakan oleh : dunia pendidikan; siswa.

6. Implementasi kebijakan TIK e-learnig dan governance sejalan dengan paradima, visi, misi dan nilai-nilai/ norma-norma pendidikan.

7. Implementasi kebijakan TIK e-learnig dan governance merupakan salah satu mata rantai kebijakan peningkatan mutu pendidikan mencakup: Formulasi; Legislasi dan adopsi; Pelaksanaan dan pengen-dalian, monitoring.; Evaluasi kinerja kebijakan peningkatan mutu pendi-dikan.

8. Dalam Implementasi kebi-jakan TIK e-learnig dan governance selalu ada perubahan-perubahan yang dinamis dari demand para stakeholder yang akan berdampak pada : aspek waktu; sarana dan prasarana; sumber daya yang diguna-kan; aspek-aspek pokok dalam pelaksanaan dan pengendalian.

\section{Penutup}

Berdasarkan latar belakang dan uraian dalam pembahasan pada bab di atas, maka dapat ditarik kesimpulan bahwa: Peningkatan mutu pendidikan merupakan kebijakan pokok Renstra Depdiknas dimana upaya peningkatan mutu pendidikan dilaksanakan melalui pembelajaran dan pelatihan TIK elearning dan e-governance bagi Guru dan Tenaga Kependidikan.

Implementasi dan pengendalian kebijakan peningkatan mutu pendidikan melalui Pembelajaran dan Pelathan e-learning dan e-governance bagi guru dan tenaga kependidikan, dengan tujuan agar kebijakan dapat segera tercapai dengan dampak negarif yang sekecil mungkin, dengan prinsip antara lain; (1) yang paling bertanggungjawab, adalah Depdiknas, guru dan tenaga kependidikan; (2) Orientasi pada peningkatan mutu pendidikan; (3) efektif, efiien dalam penggunaan sumberdaya; (4) Sesuai prosedur yang telah ditetapkan; (5) dan akuntabilitas pelaksanaan.

Proses implementasi kebijakan dilaksanakan mulai dari Sosialisai dan deseminasi kebijakan sampai pada pelaporan hasil pelaksanaan, dimana Depdiknas sebagai pelaksana yang paling bertanggungjawab dengan 
memperhatikan prinsip-prinsip efektifitas, efesiensi, sesuai prosedur, dan akuntabilitas, yang dilaksanakan secara konsekwen dan transparan. Demikian pula guru dan tenaga kependidikan sebagai pelaku utama yang dikenakan oleh kebijakan tersebut dengan penuh kesungguhan mengikuti, mempelajari, memiliki pengeahuan TIK untuk peningkatan mutu pembelajaran dan pelayanan akademik bagi terwujudnya peningkatan mutu pendidikan secara nasional.

Keberhasilan kebijakan dalam implementasi, tentunya tergantung pada komitmen, kesungguhan, ketekunan, teraktualisasi dalam mutu kinerja para pelaksana (SDM) nya. Dengan kata lain implementasi kebijakan peningkatan mutu pen-didikan melalui pembelajaran dan pelatihan guru dan tenaga kependidikan akan dapat dicapai tergantung pada kualitas kinerja Human Resources dari para pelaku kebijakannya.

\section{DAFTAR PUSTAKA}

Depdiknas. 2004. Kebijakan Renstra Depdiknas 2004-2009. Jakarta

Depdiknas. 2008. Laporan Kerja: Media Jardiknas. media.diknas.go.id

Eka Iman Prabawa.file://C:/Documents\%20and\%20Settings/masluyah /Local\%20 SettingsTemporary\%20Internet\%20Files/Content.IE5/ JXZJ2SD4/F_URGENS 1\%5B1\%5D.HTM

Fakry Gaffat: (Materi perkuliahan Kamis, 16 Oktober 2008)

Patton, Carl V., \& David S. Sawicky. 1993. Basic methods of Policy Analysis and Planning, London: Prentice-Hall.

Soendjoyo, Hadwi. Mei 2005. Prosiding Konferensi Nasional TIK. Implementasi

E-Government Sejumlah Pemerintah Daerah. Bandung : ITB.

Sutarnyoto. SKM.Msi.

file://C:/Documents\%20and\%20Settings/masluyah/Local\%20

Settings/Temporary\%20Internet\%20Files/Content.IE5/JXZJ2SD4/F_RESU ME 1\%5B2\%5D.HTM

William N. Dunn. 2000. Pengantar Analisis Kebijakan Publik. Yogyakarta:

GajahMada UniversityPress. 